\title{
The Impact of Cation Distribution on The Structural and Magnetic Properties of Nonstoichiometric Co0.5Ni0.5+xFe2-xO4 Nanoferrites
}

Adel Maher Wahba ( $\square$ a_m_wahba@yahoo.co.uk)

Tanta University Faculty of Engineering https://orcid.org/0000-0002-5629-4701

\section{Bahaa Eldeen M. Moharam}

Tanta University Faculty of Engineering

Aya Fayez Mahmoud

Tanta University Faculty of Engineering

\section{Research Article}

Keywords: nanoferrites, nonstoichiometry, autocombustion; IR, magnetic properties, cation distribution

Posted Date: February 22nd, 2021

DOl: https://doi.org/10.21203/rs.3.rs-217367/v1

License: (c) (i) This work is licensed under a Creative Commons Attribution 4.0 International License.

Read Full License 


\title{
The impact of cation distribution on the structural and magnetic properties of nonstoichiometric
}

\section{$\mathrm{Co0}_{.5} \mathrm{Ni}_{0.5+x} \mathrm{Fe}_{2-x} \mathrm{O}_{4}$ nanoferrites}

Adel Maher Wahba ${ }^{1},{ }^{*}$ Bahaa Eldeen M. Moharam ${ }^{1}$, Aya Fayez Mahmoud ${ }^{1}$

${ }^{1}$ Department of Engineering Physics and Mathematics, Faculty of Engineering, Tanta University, Egypt.

* Corresponding author. E-mail addresses: ﹎_m_wahba@yahoo.co.uk, adel.mousa@f-eng.tanta.edu.eg

\begin{abstract}
In this work, the impact of nonstoichiometric substitution of $\mathrm{Fe}^{3+}$ cations by $\mathrm{Ni}^{2+}$ ones on the structural and magnetic properties of $\mathrm{Co}_{0.5} \mathrm{Ni}_{0.5+x} \mathrm{Fe}_{2-x} \mathrm{O}_{4}(0.0 \leq x \leq 0.4)$ nanoferrites synthesized by citric autocombustion method. The cubic phase purity for sintered samples were verified by XRD patterns and FTIR spectra. The crystallite size and microstrain were deduced using Williamson-Hall method. The estimated crystallite size ranges from 55 to $89 \mathrm{~nm}$ in agreement with TEM microimages. Hysteresis loops traced using VSM prevailed a regular reduction of saturation magnetization with Ni substitution. Relied on the experimental data of XRD, FTIR, and VSM, cation distribution has been suggested, according to which the nonstoichiometric substitution was compensated by the appearance of higher valance states of $\mathrm{Fe}, \mathrm{Ni}$, and Co cations. The suggested cation distribution successfully explained the recorded data of lattice parameter, crystallite size, IR frequencies, magnetization and coercivity.
\end{abstract}

Keywords: nanoferrites; nonstoichiometry; autocombustion; IR; magnetic properties; cation distribution. 


\section{Introduction}

For decades, nanoferrites have been the subject of great interest due to their distinct optical, structural, mechanical and magnetic properties in addition to high chemical and thermal stabilities. Such unique characteristics have launched those materials as a superior choice in many applications including hyperthermia [1], sensors [2], catalysis [3], magnetic resonance imaging [4], high density data-storage [5], rechargeable battery [6] and drug delivery [7]. The preparation method has its significant effect on the structural and magnetic properties of nanoferrites [8]. Several methods have been reported for synthesizing nanosized materials such as sol-gel autocombustion [9], chemical co-precipitation [10], hydrothermal [11] and microwave combustion [12]. Among those, citrate autocombustion method is considered as a superior choice for its atomic-scale composition control and capability to produce nanoparticles at low sintering temperatures. In many cases, further heat treatment is not necessary [13].

Spinel nanoferrites are denoted by the chemical formula $\mathrm{MB}_{2} \mathrm{O}_{4}$ where $\mathrm{M}$ represents a divalent cation or a combination of more, such as $\mathrm{Co}, \mathrm{Ni}, \mathrm{Zn}$... etc. For ferrites, the trivalent element $\mathrm{B}$ is $\mathrm{Fe}$ with (or without) one of the substituents $\mathrm{Cr}, \mathrm{Al}, \ldots$ etc. [13]. When the ionic radii of the constituting cations are comparable, cubic spinel ferrites is formed; if not, less symmetric ferrites are encountered, such as hexagonal $\mathrm{SrFe}_{2} \mathrm{O}_{4}$ [14] and orthorhombic $\mathrm{BaFe}_{2} \mathrm{O}_{4}$ [15]. The unit cell of cubic spinels consists of eight formula units (octants) with 32 oxygen atoms residing at the vertices of a face-centered lattice. The metallic cations occupy the tetrahedral (A) and the octahedral (B) sites. Among the 64 available tetrahedral sites, only 8 occupy by the metallic cations, while the other cations reside at half of the 32 octahedral sites. For normal spinels, such as $\mathrm{ZnFe}_{2} \mathrm{O}_{4}$, B sites are occupied only by trivalent cations and divalent ones occupy A sites. For inverse spinels, as $\mathrm{NiFe}_{2} \mathrm{O}_{4}$, trivalent cations divided equally between $\mathrm{A}$ and $\mathrm{B}$ sites and the divalent ones reside at the remaining B sites. Such perfect normal or inverse spinels are usually 
reported for bulk ferrites. Upon merging into the nanoscale regime, significant deviations are encountered concerning the preferred occupancy of cations such as $\mathrm{Zn}$ and Ni [16].

Structural and magnetic properties of spinel ferrites are strongly dependent on the cations' occupancy along the A and B sites [17], which is affected by the method of preparation, sintering conditions, chemical composition and types of substitutions. As an illustration, the magnetic behavior of a spinel ferrite is correlated with the A-B superexchange interactions between the spins of magnetic cations and their distribution in the octahedral and tetrahedral sites [18]. Superexchange interactions are responsible for the ferrimagnetic behavior of spinel ferrites according to the two sub-lattice model [19], where the magnetic spins of the cations at the tetrahedral sites align antiparallelly to those at the octahedral ones. For a stoichiometric ferrite, the positive charge of cations balances with that of oxygen anions, while nonstoichiometry has been intendedly introduced aiming to both analyze and improve their magnetic [20, 21], electrical [22] and optical properties [23].

Nickel ferrite is distinguished by its moderate magnetization, low coercivity, high resistivity, and is thus classified as soft magnetic and low electrical-loss material $[24,25]$ and thus used as gas sensors, catalysts, and ferrofluid. On the other hand, hard ferrimagnetic cobalt ferrite is characterized by its relatively high magnetization, lower resistivity, excellent chemical stability, mechanical hardness, and high coercivity, and thus suitable for high-density magnetic recording applications [26]. In fact, the presence of $\mathrm{Co}^{2+}$ ions in the octahedral sites is the origin of the distinct magnetocrystalline anisotropy for $\mathrm{CoFe}_{2} \mathrm{O}_{4}$ [27]. Other cations such as $\mathrm{Fe}^{2+}$ and $\mathrm{Ni}^{3+}$ play the same role as $\mathrm{Co}^{2+}$ when reside at $\mathrm{B}$ site [27]. Beside possessing low magnetocrystalline anisotropy, $\mathrm{Ni}^{+2}$ prefers $\mathrm{B}$-site occupancy more than $\mathrm{Co}^{2+}$. Consequently, when content of $\mathrm{Ni}^{2+}$ increases in a nanoferrite, some of $\mathrm{Co}^{2+}$ ions are forced to migrate from $\mathrm{B}$ to A sites providing an effective way to moderate the anisotropy of $\mathrm{CoFe}_{2} \mathrm{O}_{4}$. Thus, nickel cobalt 
ferrites exhibit high saturation magnetization combined with moderate coercivity [28-32], which is really beneficial in many potential applications.

In this work, we have investigated the effect of the nonstoichiometric substitution of $\mathrm{Fe}^{3+}$ by $\mathrm{Ni}^{2+}$ on the structural and magnetic properties of $\mathrm{C}_{0.5} \mathrm{Ni}_{0.5+x} \mathrm{Fe}_{2-x} \mathrm{O}_{4}(0.0 \leq x \leq 0.4)$ nanoferrites synthesized by autocombustion method. Structural characteristics from X-ray, FTIR spectra and TEM imaging, and magnetic properties from VSM hysteresis loops have been analyzed. Although the ionic radius of $\mathrm{Ni}^{+2}$ cation is relatively large compared to that of $\mathrm{Fe}^{3+}$, the lattice parameter did not show a regular increase with $x$. In addition, both coercivity and crystallite size behaved nonmonotonically with Ni substitution. To explain such anomalous behaviors, the cation distribution of each single-phase sintered sample has been proposed on the basis of the experimental parameters of lattice parameter, vibrational IR frequencies and magnetization. The matching of such cation distribution with the behavior of the structural and magnetic properties has been analyzed in detail.

\section{Experimental}

Nano-sized $\mathrm{Co}_{0.5} \mathrm{Ni}_{0.5+x} \mathrm{Fe}_{2-x} \mathrm{O}_{4}(0.0 \leq x \leq 0.4)$ were prepared by citrate autocombustion method using citric acid as a fuel. Estimated amounts of cobalt nitrate $\mathrm{Co}\left(\mathrm{NO}_{3}\right)_{2} \cdot 6 \mathrm{H}_{2} \mathrm{O}$, nickel nitrate $\mathrm{Ni}\left(\mathrm{NO}_{3}\right)_{2} \cdot 6 \mathrm{H}_{2} \mathrm{O}$ and iron nitrate $\mathrm{Fe}\left(\mathrm{NO}_{3}\right)_{3} .9 \mathrm{H}_{2} \mathrm{O}$ ( purchased from Merck), in additional to anhydrous citric acid $\mathrm{C}_{6} \mathrm{H}_{8} \mathrm{O}_{7}$ were used as starting materials. Citric to metal ratio was chosen to be $1: 1$ for the whole samples. The metal nitrates act as oxidants, while citric acid acts as a fuel. Appropriate amounts of the metal salts were dissolved in minimum amounts of deionized water and metal solutions were mixed together using a magnetic stirrer. Citric-acid solution was then added, and ammonium hydroxide solution was added drop by drop to adjust the $\mathrm{pH}$ number from 1 to 7 , followed by further stirring for one hour. The mixture temperature was then raised to $90{ }^{\circ} \mathrm{C}$ to evaporate water, after which autocombustion started and spread along the whole 
brownish viscous gel converting it to a fluffy ashlike powder. After grinding in a mortar agate, a part of the powder for each sample was calcined at $600{ }^{\circ} \mathrm{C}$ for $2 \mathrm{~h}$ in a muffle furnace with a heating rate of 5 ${ }^{\circ} \mathrm{C} / \mathrm{min}$, and then left to cool down to room temperature. The Phase purity of both as prepared (Ap) and sintered samples was examined by X-ray diffraction at room temperature using Philips diffractometer (X'pert MPD) with a goniometer using $\mathrm{Cu}-\mathrm{K} \alpha$ radiation $(\lambda=1.54056 \mathrm{~nm})$. The range of the angle $2 \theta$ was chosen along $15-80^{\circ}$ with a step of $0.03^{\circ}$ and step time $1.5 \mathrm{~s}$. In terms of the plane-spacing $(d)$ and Miller indices $(h, k, l)$, the lattice parameter $(a)$ has been estimated for each diffraction peak using $a=$ $d \sqrt{h^{2}+k^{2}+l^{2}}$. The XRD density ( $\left.\rho_{\mathrm{XRD}}\right)$ was estimated for each sample using the relation [33] $\rho_{\mathrm{XRD}}=$ $8 M_{\mathrm{w}} /\left(N_{\mathrm{A}} a^{3}\right)$, where the factor 8 denotes the number of chemical formulas per unit cell, $M_{\mathrm{w}}$ is the molecular weight, $N_{\mathrm{A}}$ is Avogadro's number and $a^{3}$ is the unit-cell volume. The crystallite size of each sintered sample was obtained using Williamson-Hall method that assumes a uniform and isotropic strain. In that method, plots were drawn according to the equation [34]: $\beta_{h k l} \cos \theta_{h k l}=4 \varepsilon \sin \theta_{h k l}+K \lambda / D$, where $2 \theta$ is the Bragg diffraction angle at the diffraction plane $(h k l)$ with $d_{h k l}$ spacing, $\beta_{h k l}$ is the fullwidth half-maximum (FWHM) of the corresponding XRD peak, and the value of the constant $K$ is taken as 0.9 frequently used for ferrites particles. The crystallite size is deduced from the $y$-intercept of the straight line that fits the data of $\beta_{h k l} \cos \theta_{h k l}$ versus $4 \varepsilon \sin \theta_{h k l}$, while the slope is used to determine the microstrain $(\varepsilon)$.

Fourier-transform infrared (FTIR) spectra (Bruker Tensor 27 FTIR Spectrometer) were recorded at room temperature in the range of $200-1000 \mathrm{~cm}^{-1}$ to confirm the standard vibrational bands corresponding to the spinel structure and to analyze variations in the vibrational frequency with nickel substitution. Such variations are usually quite helpful when suggesting the cation distribution. The morphology, size and shape of the studied samples were investigated through images recorded by transmission electron microscopy (TEM, JEOL JEM-1200EXII) with an accelerating voltage up to $120 \mathrm{kV}$. The magnetic 
characteristics of each sample including saturation magnetization, coercivity, and remanent field were acquired using $M-H$ hysteresis loops traced via vibrating sample magnetometry (VSM model 9600) with an applied magnetic field that extends up to $20 \mathrm{kOe}$.

\section{Results and discussion}

\subsection{Structural Properties}

The XRD pattern of $\mathrm{Ap} \mathrm{Co}_{0.5} \mathrm{Ni}_{0.9} \mathrm{Fe}_{1.6} \mathrm{O}_{4}$ sample (0.4Ap) and those of $\mathrm{Co}_{0.5} \mathrm{Ni}_{0.5+x} \mathrm{Fe}_{2-x} \mathrm{O}_{4}(x=0.0-0.4$, step 0.1) ones sintered at $600{ }^{\circ} \mathrm{C}$ for $2 \mathrm{~h}$ are illustrated in Fig. 1. Cubic phase formation has been confirmed for all samples as indicated by peaks corresponding to the diffraction planes (111), (220), (311), (222), (400), (422), (511), (440), (620), (533) and (622) indexed for the cubic phase of spinel ferrites [JCPDS cards: 22-1086 for $\mathrm{CoFe}_{2} \mathrm{O}_{4}$ and 03-0875 for $\left.\mathrm{NiFe}_{2} \mathrm{O}_{4}\right]$. Meanwhile, minute traces of impurity phases were observed for Ap samples; definitely hexagonal hematite [35, 36] and cubic Ni-element phases [37, 38]. Such phases and their relative concentrations are clarified in Fig. 1 for $0.4 \mathrm{Ap}$ sample with highest degree of nonstoichiometry. In addition, the presence of $\mathrm{NiO}$ cubic phase in Ap samples should not be excluded as its XRD peaks are quite coincident with those of cubic spinel ferrites [39]. Actually, $\mathrm{NiO}$ and $\mathrm{Fe}_{2} \mathrm{O}_{3}$ could be regarded as intermediate phases before the formation of the cubic nanoferrites. Upon sintering process, the impurity phases almost disappeared in all sintered samples [40] as exhibited in Fig. 1. The recorded XRD data have been used to get the lattice parameter $(a)$ along with XRD density $\left(\rho_{\mathrm{XRD}}\right)$. Values of $a$ and are listed in Table 1 for sintered $\mathrm{Co}_{0.5} \mathrm{Ni}_{0.5+x} \mathrm{Fe}_{2-x} \mathrm{O}_{4}$ samples. As expected, $\rho$ XRD increases monotonically with the nickel substitution as the effect of molecular weight dominates.

The lattice parameter is expected to have a monotonic increase with nickel substitution because the ionic radius of $\mathrm{Ni}^{2+}$ cation for either $\mathrm{A}$ or B site $\left(0.55\right.$ and $0.69 \AA$, respectively) is larger than that of $\mathrm{Fe}^{3+}$ ( 0.49 and $0.645 \AA$ A). However, the lattice parameter generally decreased with the doped nickel substitution $(x)$ as shown in Fig. 2. Worth to mention is that the $2 \theta$ positions of the (311) diffraction planes (see right 
part of Fig. 1) agree with the variation of $a$ with $x$. Such variation can be explained as follows. The nonstoichiometric substitution of $\mathrm{Fe}^{3+}$ by $\mathrm{Ni}^{2+}$ is most likely to be compensated by the oxidation of the involved cations $\left(\mathrm{Co}^{2+}, \mathrm{Ni}^{2+}\right.$, and $\left.\mathrm{Fe}^{3+}\right)$ to higher valance states to recover charge neutrality [41]. Concentration of such higher-valence cations further increased after the sintering process that provides extra oxidation energy. Higher valence cation has smaller ionic radii and reduction of lattice parameter is thereby expected. In Fig. 1, comparing the $2 \theta$ position of (311) plane for 0.4 and 0.4 Ap samples confirms lattice parameter reduction with sintering process.

The plots corresponding to Williamson-Hall method used to obtain crystallite size and microstrain are shown in Fig. 3 along with the corresponding $R^{2}$ values. Values of the crystallite size and the microstrain estimated from Williamson-Hall method for sintered sample are listed in Table 1. The estimated microstrain of the sintered samples almost behaves in the same manner as that of the crystallite size, which indicates the dominating effect of grain boundaries density over that of the crystallite growth. Besides removing the secondary phases observed in Ap samples, the sintering process improves samples crystallinity, enhances nanocrystals growth, and reduces structural defects. As indicated in Fig. 2 and Table 1 , the crystallite size of the sintered samples mostly reduced with increasing $\mathrm{Ni}^{2+}$ substitution. As will be discussed later, the crystallite growth is affected by the relative distribution of $\mathrm{Fe}^{3+}$ cations along the octahedral and tetrahedral sublattices. Since $\mathrm{Ni}^{2+}$ has a stronger preference to occupy $\mathrm{B}$ site than $\mathrm{Co}^{2+}$, cobalt-nickel ferrites often decrease in size with increasing Ni/Co ratio [36] that reduces $\mathrm{Fe}^{3+}$ occupation in $\mathrm{B}$ site. In addition, the accumulation of $\mathrm{Ni}^{2+}$ ions on the grain boundary during the sintering process could hinder the grain growth [31]. This will be discussed in detail when considering cation distribution of the investigated sintered samples.

FTIR spectra of $\mathrm{Co}_{0.5} \mathrm{Ni}_{0.5+x} \mathrm{Fe}_{2-} \mathrm{O}_{4}$ sintered samples are shown in Fig. 4a. Generally, IR spectra are usually used to confirm the cubic spinel structure of the investigated samples through the two main 
vibrational bands corresponding to tetrahedral and octahedral sublattices. In addition, tracing the variation in the vibrational frequencies of those bands provide reasonable visualization when suggesting the cation distribution. As illustrated in Table 1, the higher-absorption band $v_{1}$ appeared in the frequency range from 576.9 to $580.3 \mathrm{~cm}^{-1}$ and corresponds to the stretching vibrations of the $\mathrm{Fe}^{3+}-\mathrm{O}$ bonds at the tetrahedral site. The lower-frequency band $v_{2}$ with the range of 378.2 to $392.2 \mathrm{~cm}^{-1}$ is attributed to the bending $\mathrm{Fe}^{3+}-\mathrm{O}$ vibrations in the octahedral site. The open circle elucidated in Fig. $4 a$ at around $470 \mathrm{~cm}^{-1}$ for sample with $x=0$ indicates the presence of $\mathrm{Fe}^{2+}$ cation $[13,42]$. To explain the effect of the sintering process, Fig. $4 b$ shows the IR spectra for both Ap and sintered samples with $x=0.2$, which shows the sharpening of $\mathrm{Fe}^{3+}-\mathrm{O}$ bands in both sublattice sites as a result of the significant improvement of crystallization upon sintering. Remarkably, the tetrahedral absorption band $v_{1}$ remarkably shifts from 538 to $577 \mathrm{~cm}^{-1}$ upon sintering, while the octahedral band is slightly decreased (dashed lines in Fig. $4 b$ ). This shift in $v_{1}$ reflects a noticeable shrinkage of the tetrahedral sublattice size. Sintering process facilitates $\mathrm{Ni}^{2+}$ and $\mathrm{Fe}^{3+}$ cations (from impurity phases) to be inserted in the cubic structure. Preference of Ni cations to occupy the B site enforces $\mathrm{Fe}^{3+}$ cations to migrate to A site, which explains the recorded remarkable shift of $v_{1}$.

Interestingly, the octahedral absorption band $v_{2}$ shifts toward higher frequencies with increasing the nickel content as indicated in Table 1. In fact, $v_{2}$ is expected to decrease with $\mathrm{Ni}^{2+}$ due to its larger ionic radius (relative to $\mathrm{Fe}^{3+}$ ) beside its high tendency to occupy $\mathrm{B}$ site. As mentioned before, the nonstoichiometric $\mathrm{Fe}^{3+}-\mathrm{Ni}^{2+}$ substitution enhanced the formation of higher valence states of the involved cations, which is more confirmed by the weak absorption bands $\left(v_{3}-v_{6}\right)$ observed in Fig. 4 at relatively high frequencies [43]. Such high-frequency bands were even observed for the stoichiometric sample $(x=$ 0 ) due to the presence of $\mathrm{Fe}^{2+}$ cations. Besides the induced nonstoichiometry, the sintering process enhanced the formation of such higher valance states [44-46], which is more confirmed by comparing the two insets of Figs. $4 a$ and $b$. The insets illustrate the high-frequency bands for Ap and sintered samples 
with $x=0.2$, respectively. Indeed, the sharpness of such bands increased upon the sintering process excluding the role of any organic residuals [47]. In fact, the characteristics bands corresponding to organic groups are observed at higher frequencies [48], while vibrations assigned to the IR absorption bands in the crystal lattice are typically located in the range of $100-1000 \mathrm{~cm}^{-1}[49,50]$. The four weak bands have been explained as follows. Bands $v_{3}$ and $v_{4}$ at $~ 820 \mathrm{~cm}^{-1}$ and $865 \mathrm{~cm}^{-1}$ correspond to $\mathrm{Fe}^{4+}[51,52]$ and $\mathrm{Ni}^{3+}$ $[53,44]$ bonds, respectively. The absorption bands $v_{5}$ and $v_{6}$ at $\sim 950$ and $980 \mathrm{~cm}^{-1}$ probably originate from $\mathrm{Ni}^{4+}-$ and $\mathrm{Co}^{4+}$-oxygen bonds. Such two cations have been reported in several nonstoichiometric ferrites $[54,55]$. Regarding the insets of Figs. $5 a$ and $b$, the two bands corresponding to $\mathrm{Ni}^{4+}$ and $\mathrm{Co}^{4+}$ cations are distinguished for AP sample, while overlapping for the sintered one due to the increase in concentration. Similar high-frequency bands were recorded with no explanation for Ni-Co ferrites $[31,56]$. The cation $\mathrm{Co}^{4+}$ occupy tetrahedral site, while $\mathrm{Fe}^{4+}, \mathrm{Ni}^{3+}$, and $\mathrm{Ni}^{4+}$ occupy octahedral states. This explains the slight reduction in the octahedral sublattice size with $x$ despite the increase of larger $\mathrm{Ni}^{2+}$ content. It further explains the general reduction of the lattice parameter with $\mathrm{Fe}^{3+}-\mathrm{Ni}^{2+}$ substitution.

TEM images have been used to assess the average particle size and size distribution of the investigated nanoferrites, and also to give a better view of the particles' morphology and shape. The nanosized scale of the investigated sample was confirmed using the TEM microimage taken for the highly nonstoichiometric sintered sample with $x=0.4$, as shown at Fig. 5. The average crystallite size obtained from TEM image matches well with that estimated from XRD data (Table 1). The nano-particles generally exhibit an almost deformed cubic shape, as indicated by the arrows in Fig. 5. In addition, the strong tendency for agglomeration is attributed to the magnetic interactions and/ or their small size. The relatively wide range of the particles size in the sample is considered as a drawback of the autocombustion preparation method. 


\subsection{Magnetic properties}

The magnetic characterization for $\mathrm{Co}_{0.5} \mathrm{Ni}_{0.5+x} \mathrm{Fe}_{2-x} \mathrm{O}_{4}(0 \leq x \leq 0.4)$ samples sintered at $600{ }^{\circ} \mathrm{C}$ has been investigated by tracing $M-H$ hysteresis loops at room temperature, as shown in Fig. 6, with an applied field extending to 2 T. Figure 6 also shows the hysteresis loop for Ap sample with $x=0.2(0.2 \mathrm{Ap})$ for comparison. Hysteresis loops were used to deduce the magnetic parameters for the investigated samples including the magnetization at an applied magnetic field of $20 \mathrm{kOe}\left(M_{20}\right)$, the saturation magnetization $\left(M_{\mathrm{s}}\right)$, remanence $\left(M_{\mathrm{r}}\right)$ the coercive field $\left(H_{\mathrm{c}}\right)$, and squareness ratio $\left(S Q=M_{\mathrm{r}} / M_{\mathrm{s}}\right)$. The saturation magnetization $\left(M_{\mathrm{s}}\right)$ was obtained using the interpolation of $M$ vs. $1 / H$ curves as $H$ approaches infinity [57]. Values of the above magnetic parameters are listed in Table 2. The comparatively small deviations of $M_{20}$ from $M_{\mathrm{S}}$ values suggest that the investigated samples were quite close to saturation within the range of the applied field. Moreover, SQ values for all sintered samples are close to the 0.5 -value corresponding to the single-domain ferrimagnetic particles [58].

Considering the sintered samples, $M_{\mathrm{s}}$ decreases almost linearly with increasing nickel substitution, as indicated in Fig .7, which is quite expected due to the substitution of $\mathrm{Fe}^{3+}$ with higher magnetic moment $\left(5 \mu_{\mathrm{B}}\right)$ by $\mathrm{Ni}^{2+}\left(2 \mu_{\mathrm{B}}\right)$. Moreover, both the appearance of higher-valence less-magnetic cations and the partial migration of the remaining $\mathrm{Fe}^{3+}$ cations to A site also suppress $M_{\mathrm{s}}$ values. The coercivity of sintered samples varies inversely with the crystallite size for $x \geq 0.2$ (see Figs. 2 and 7). For $x \leq 0.1$, a different parameter, the cation distribution, dominates the coercivity behavior. In fact, the crystallite size and the cation distribution both affect the coercivity behaviour as will be discussed in detail when considering the cation distribution of the sintered samples.

The effect of the sintering process could be inferred by comparing the values of $M_{\mathrm{s}}, H_{\mathrm{c}}$, and SQ for Ap and sintered samples with $x=0.2$ (Table 2 and Fig. 6). Sintering process suppressed the whole magnetic parameters of the samples, which could be attributed to three possible reasons: (1) the formation 
of higher-valence less-magnetic cations to recover the stoichiometry; (2) cation redistribution, which could be correlated with the IR spectra (insets of Fig. 4); and (3) the increase in the crystallite size above the critical size, which is reflected in the significant reduction in coercivity. Despite the increase of the crystallite size upon sintering, reasons 1 and 2 explain the recorded reduction of $M_{\mathrm{s}}$.

\subsection{Proposed Cation Distribution}

The cation distribution has been proposed for the sintered samples according to the experimental data including the lattice parameter estimated from XRD data, vibrational frequencies obtained from IR spectra, and the saturation magnetization from $M-H$ loops. The experimental values of the magnetic moment per formula unit for each sintered sample, $n_{\exp }$ (listed in Table 2) were estimated from the values of $M_{\mathrm{s}}$ according to the relation [33]: $n_{\exp }=M_{\mathrm{w}} \times M_{\mathrm{s}} / 5585$ where $M_{\mathrm{w}}$ is the molecular weight of each composition and $M_{\mathrm{s}}$ is the saturation magnetization (Table 2). Generally, the magnetic moments for the cations at A and B sites in spinel ferrites are antiparallel to each other and according to Néel model, the overall magnetization is estimated as $n_{\text {Néel }}=M_{\mathrm{B}}-M_{\mathrm{A}}$ [28], where $M_{\mathrm{A}}$ and $M_{\mathrm{B}}$ are the sum of the magnetic moments of the involved cations at tetrahedral and octahedral sublattices, respectively. For nanosized ferrites, sample magnetization is properly assumed to follow the Yafet-Kittel model, for which the octahedral magnetic spins are divided into two components canted at an angle $\pm \theta_{c}$. For such a case, the theoretical magnetic moment per formula unit is estimated as $n_{Y-K}=M_{\mathrm{B}} \cos \theta_{\mathrm{c}}-M_{\mathrm{A}}$ [28]. For the Néel model, the canting angle is zero. The sublattice magnetic moments $M_{\mathrm{A}}$ and $M_{\mathrm{B}}$ are obtained from the suggested cation distribution as follow: $M_{i}=\sum c_{\alpha} \mu_{\alpha}$, where $c_{\alpha}$ is the concentration of the cation $\alpha$ which has magnetic moment $\mu_{\alpha}$ in the site $i$. In this work, the magnetic moment for the involved cations in terms of the Bohr magneton $\left(\mu_{\mathrm{B}}\right)$ are: 2 for $\mathrm{Ni}^{2+}, 3$ for $\mathrm{Ni}^{3+}$ and $\mathrm{Co}^{2+}, 4$ for $\mathrm{Fe}^{2+}$ and $\mathrm{Fe}^{4+}, 5$ for $^{2+} e^{3+}$, and 0 for $\mathrm{Ni}^{4+}$. The cation distribution, illustrated in Table 3, has been suggested in such a way that the variation of $n_{\text {Néel }}$ with nickel substitution ( $x$ ) matches that of $n_{\text {exp }}$. In Table 3 , the parentheses and the 
square brackets represent tetrahedral and octahedral sublattices, respectively. The canting angles were evaluated by equating $n_{\mathrm{Y}-\mathrm{K}}$ with $n_{\exp }$ using values of $M_{\mathrm{A}}$ and $M_{\mathrm{B}}$ estimated from the cation distribution (see Table 2).

On the basis of the proposed cation distribution, the sublattice radii $r_{\mathrm{A}}$ and $r_{\mathrm{B}}$ of the tetrahedral and octahedral sites, respectively have been estimated using the formula [33]: $r_{\mathrm{A}}=\sum_{i} \alpha_{i} r_{i} \& r_{\mathrm{B}}=\frac{1}{2} \sum_{i} \alpha_{i} r_{i}$, where $\alpha_{i}$ is the concentration of the cation $i$ with ionic radius $r_{i}$ at the corresponding site. Values used for $r_{i}$ are: $\mathrm{Co}^{+2}\left(0.58\right.$ and $0.745 \AA$ for $\mathrm{A}-$ and $\mathrm{B}$-site, respectively), $\mathrm{Ni}^{2+}(0.55$ and $0.69 \AA), \mathrm{Fe}^{3+}(0.49$ and 0.645 $\AA), \mathrm{Co}_{\AA}^{4+}(0.40 \AA), \mathrm{Ni}_{\mathrm{B}}^{3+}(0.56 \AA), \mathrm{Ni}_{\mathrm{B}}^{4+}(0.48 \AA), \mathrm{Fe}_{\mathrm{B}}^{2+}(0.78 \AA)$ and $\mathrm{Fe}_{\mathrm{B}}^{4+}(0.585 \AA)$. The theoretical lattice parameter for each sample was then calculated according to the relation [33]: $a_{\mathrm{th}}=(8 / 3 \sqrt{3})\left[\left(r_{\mathrm{A}}+R_{\mathrm{o}}\right)+\right.$ $\left.\sqrt{3}\left(r_{\mathrm{B}}+R_{\mathrm{o}}\right)\right]$, where $R_{\mathrm{o}}$ is the ionic radius of oxygen anion.

To ensure its validity, theoretical parameters deduced from the proposed cation distribution should agree with the available experimental data. Firstly, when proposing the cation distribution, the mismatching between $a_{\mathrm{th}}$ and $a_{\exp }$ was restricted to be less than $10^{-4} \AA$. considering VSM data, the variation of the magnetic moment per formula unit $n_{\text {Néel }}$ with nickel substitution agrees quite reasonably with that of $n_{\text {exp }}$, as illustrated in Fig. 8, where the deviation between their values is attributed to the nanoscale nature of the samples and/or local canting mechanisms. Furthermore, the variation of the estimated sublattice radii $\left(r_{\mathrm{A}}\right.$ and $\left.r_{\mathrm{B}}\right)$ with Ni substitution $(x)$, as illustrated in Fig. 9, has shown a reverse trend with the variation of the vibrational frequencies $\left(v_{1}\right.$ and $\left.v_{2}\right)$ obtained from IR spectra: shorter bond lengths produce higher vibrational frequencies and vice versa.

On attempting to correlate the recorded coercivity with the cation distribution, the effect of the crystallite size should not be ignored. In fact, the coercivity of fine magnetic particles is strongly affected by the crystallite size and the microstrain besides the presence of magnetocrystalline anisotropic cations 
and their occupancy. As mentioned above, the crystallite size of samples under study generally exceeded the critical value, since $H_{\mathrm{c}}$ varies almost inversely with $D$ for $x>0.1$, as indicated in Fig. $10 a$ and $b$. To examine the effect of anisotropic cations, a cation-distribution parameter $(C D P)$ was suggested with the formula: $C D P=\left(\mathrm{Co}_{\mathrm{B}}^{2+}+\mathrm{Fe}_{\mathrm{B}}^{2+}+\mathrm{Ni}_{\mathrm{B}}^{3+}\right) /\left[\left(\mathrm{Fe}_{\mathrm{B}}^{3+}+\mathrm{Fe}_{\mathrm{B}}^{4+}\right)\left(\mathrm{Ni}_{\mathrm{B}}^{2+}+\mathrm{Ni}_{\mathrm{B}}^{4+}\right)\right]$, where each cation symbol indicates its concentration (from Table 3) in the octahedral site. This parameter influences the coercivity $H_{\mathrm{c}}$ as follows: the numerator includes the highly magnetocrystalline anisotropic $\mathrm{Fe}^{2+}, \mathrm{Co}^{2+}$ and $\mathrm{Ni}^{3+}$ cations [59], while the cations of the denominator affect the surroundings of the anisotropic cations and the corresponding nearest-neighbor distance [27]. Variation of CDP (Fig. 10a) matches well with that of $H_{\mathrm{c}}$ for $x<0.2$. Interestingly, quite similar behavior for both $H_{\mathrm{c}}$ and the quotient $C D P / D$ with nickel substitution $x$ as illustrated in Fig. $10 b$.

Despite the well-known fact that the crystallite size is mainly controlled by the preparation method and the heat treatment of the samples, the cation distribution could be regarded as a primary factor that affect the crystallite size. As half of the 16 octahedral sites and just one eighth of the 64 tetrahedral sites are occupied with metal cations, most of the particle surface area contains octahedral-occupied cations. As mentioned before, the presence of more $\mathrm{Fe}^{3+}$ cations in the octahedral sites is expected to enhance the crystallite growth. For this reason, cobalt ferrite particles are generally larger in size than nickel ferrite prepared under the same conditions [24, 30, 40, 60]. Figure 11 illustrates both the occupation ratio of $\mathrm{Fe}^{3+}$ cations $\left(\mathrm{Fe}_{\mathrm{B} / \mathrm{A}}^{3+}=\mathrm{Fe}_{\mathrm{B}}^{3+} / \mathrm{Fe}_{\mathrm{A}}^{3+}\right)$ and the crystallite size $D$ for the recent samples, which confirms the direct correlation between $D$ and the relative accumulation of $\mathrm{Fe}^{3+}$ cations in the octahedral side.

\section{$\underline{\text { Conclusion }}$}

Single-phase nonstoichiometric $\mathrm{Co}_{0.5} \mathrm{Ni}_{0.5+x} \mathrm{Fe}_{2-x} \mathrm{O}_{4}(0.0 \leq x \leq 0.4)$ cubic nanoferrites sintered at $600{ }^{\circ} \mathrm{C}$ have been prepared by citrate autocombustion. Phase purity was confirmed through XRD patterns and IR 
spectra. Nanosized deformed cubic particles were exhibited from the TEM image. $M-H$ loops revealed reduction of magnetization with $\mathrm{Ni}$ substitution. The nonstoichiometric substitution of $\mathrm{Fe}^{3+}$ by $\mathrm{Ni}^{2+}$, in addition to the sintering process, has prompted the appearance of higher valance cations, which was revealed in IR spectra and reflected in lattice parameter reduction with $\mathrm{Ni}^{2+}$ substitution. The cation distribution for each sintered sample was proposed on the basis of the recorded data of XRD, IR, and VSM. The proposed cation distribution successfully explained the variation of the structural and magnetic parameters including lattice parameter, crystallite size, IR vibrational frequencies, saturation magnetization and coercivity with nickel substitution.

\section{References}

[1] Zhiguo Zhou, Yanan Sun, Jinchao Shen, Jie Wei, Chao Yu, Bin Kong, Wei Liu, Hong Yang, Shiping Yang, Wei Wang, Iron/iron oxide core/shell nanoparticles for magnetic targeting MRI and near-infrared photothermal therapy, Biomaterials 35 (2014) 7470-7478. https://doi.org/10.1016/j.biomaterials.2014.04.063

[2] R. Srivastava and B. C. Yadav, Ferrite materials: Introduction, synthesis techniques, and applications as sensors, Int. J. Green Nanotechnol. Biomed. 4 (2012) 141-154. https://doi.org/10.1080/19430892.2012.676918

[3] M. Amiri, K. Eskandari, and M. Salavati-Niasari, Magnetically retrievable ferrite nanoparticles in the catalysis application, Adv. Colloid Interface Sci. 271 (2019) 101982(1-10). https://doi.org/10.1016/j.cis.2019.07.003

[4] J.H. Hankiewicz, J.A. Stoll, J. Stroud, J. Davidson, K.L. Livesey, K. Tvrdy, A. Roshko, S.E. Russek, K. Stupic, P. Bilski, R.E. Camley, Z.J. Celinski, Nano-sized ferrite particles for magnetic resonance imaging thermometry, J. Magn. Magn. Mater. 469 (2019) 550-557. https://doi.org/10.1016/j.jmmm.2018.09.037

[5] Zaheer Abbas Gilani, Muhammad Shahzad Shifa, H.M. Noor ul Huda Khan Asghar, Muhammad Azhar Khan, Muhammad Naeem Anjum, Muhammad Nauman Usmani, Rajjab Ali, Muhammad Farooq Warsi, New LiCo ${ }_{0.5} \mathrm{Pr}_{x} \mathrm{Fe}_{2-} \mathrm{O}_{4}$ nanoferrites: Prepared via low cost technique for high density storage application, Ceram. Int. 44 (2018) 1881-1885.

https://doi.org/10.1016/j.ceramint.2017.10.126

[6] V. Kashyap, S. Kurungot, Zirconium-Substituted Cobalt Ferrite Nanoparticle Supported N-doped Reduced Graphene Oxide as an Efficient Bifunctional Electrocatalyst for Rechargeable Zn-Air Battery, ACS Catal. 8 (2018) 3715-3726. https://doi.org/10.1021/acscatal.7b03823 
[7] A. Nigam, S. J. Pawar, Structural, magnetic, and antimicrobial properties of zinc doped magnesium ferrite for drug delivery applications, Ceram. Int. 46 (2020) 4058-4064. https://doi.org/10.1016/j.ceramint.2019.10.243

[8] E. Petrova, D. Kotsikau, V. Pankov, A. Fahmi, Influence of synthesis methods on structural and magnetic characteristics of Mg-Zn-ferrite nanopowders, J. Magn. Magn. Mater. 473 (2019) 8591. https://doi.org/10.1016/j.jmmm.2018.09.128

[9] D. R. Mane, S. Patil, D. D. Birajdar, A. B. Kadam, S. E. Shirsath, R. H. Kadam, Sol-gel synthesis of $\mathrm{Cr}^{3+}$ substituted $\mathrm{Li}_{0.5} \mathrm{Fe}_{2.5} \mathrm{O}_{4}$ : Cation distribution, structural and magnetic properties, Mater. Chem. Phys. 126 (2011) 755-760. https://doi.org/10.1016/j.matchemphys.2010.12.048

[10] S. T. Alone, S. E. Shirsath, R. H. Kadam, K. M. Jadhav, Chemical synthesis, structural and magnetic properties of nano-structured Co-Zn-Fe-Cr ferrite, J. Alloys Compd. 509 (2011) 50555060. https://doi.org/10.1016/j.jallcom.2011.02.006

[11] M. Li, X. Liu, T. Xu, Y. Nie, H. Li, C. Zhang, Synthesis and characterization of nanosized MnZn ferrites via a modified hydrothermal method, J. Magn. Magn. Mater. 439 (2017) 228-235. https://doi.org/10.1016/j.jmmm.2017.04.015

[12] Y. Köseoğlu, A. Baykal, F. Gözüak, H. Kavas, Structural and magnetic properties of $\mathrm{Co}_{x} \mathrm{Zn}_{1-}$ ${ }_{x} \mathrm{Fe}_{2} \mathrm{O}_{4}$ nanocrystals synthesized by microwave method, Polyhedron 28 (2009) 2887-2892. https://doi.org/10.1016/j.poly.2009.06.061

[13] A. M. Wahba, M. B. Mohamed, Correlating cation distribution with the structural and magnetic properties of $\mathrm{Co}_{0.5} \mathrm{Zn}_{0.5} \mathrm{Al}_{x} \mathrm{Fe}_{2-x} \mathrm{O}_{4}$ nanoferrites, Appl. Phys. A Mater. Sci. Process. 126 (2020) 111. https://doi.org/10.1007/s00339-020-03692-2

[14] M. H. Mahmoud, A. M. Elshahawy, S. A. Makhlouf, H. H. Hamdeh, Synthesis of highly ordered $30 \mathrm{~nm} \mathrm{NiFe} 2 \mathrm{O}_{4}$ particles by the microwave-combustion method, J. Magn. Magn. Mater. 369 (2014) 55-61. https://doi.org/10.1016/j.jmmm.2014.06.011

[15] M. C. Dimri, H. Khanduri, P. Agarwal, J. Pahapill, R. Stern, Structural, magnetic, microwave permittivity and permeability studies of barium monoferrite $\left(\mathrm{BaFe}_{2} \mathrm{O}_{4}\right)$, J. Magn. Magn. Mater. 486 (2019) 165278(1-6). https://doi.org/10.1016/j.jmmm.2019.165278

[16] P. Tiwari, R. Verma, S. N. Kane, T. Tatarchuk, F. Mazaleyrat, Effect of Zn addition on structural, magnetic properties and anti-structural modeling of magnesium-nickel nano ferrites, Mater. Chem. Phys. 229 (2019) 78-86. https://doi.org/10.1016/j.matchemphys.2019.02.030

[17] K. K. Bamzai, G. Kour, B. Kaur, S. D. Kulkarni, Journal of Magnetism and Magnetic Materials Effect of cation distribution on structural and magnetic properties of Dy substituted magnesium ferrite, J. Magn. Magn. Mater. 327 (2013) 159-166. https://doi.org/10.1016/j.jmmm.2012.09.013

[18] M. A. Yousuf, S. Jabeen, M. N. Shahi, M. A. Khan, I. Shakir, M. F. Warsi, Magnetic and electrical properties of yttrium substituted manganese ferrite nanoparticles prepared via microemulsion route, Results Phys. 16 (2020) 102973(1-6). https://doi.org/10.1016/j.rinp.2020.102973 
[19] V. Tukaram, S. S. Shinde, R. B. Borade, A. B. Kadam, Physica B : Physics of Condensed Matter Study of cation distribution, structural and electrical properties of $\mathrm{Al}-\mathrm{Zn}$ substituted $\mathrm{Ni}-\mathrm{Co}$ ferrite, Phys. B Phys. Condens. Matter 577 (2020) 411783(1-6). https://doi.org/10.1016/j.physb.2019.411783

[20] Fabian H. L. Starsich, Georgios A. Sotiriou, Moritz C. Wurnig, Christian Eberhardt, Ann M. Hirt, Andreas Boss, Sotiris E. Pratsinis, Silica-Coated Nonstoichiometric Nano Zn-Ferrites for Magnetic Resonance Imaging and Hyperthermia Treatment, Adv. Healthc. Mater. 5 (2016) 26982706. https://doi.org/10.1002/adhm.201600725

[21] Hongseok Yun, Jungkwun Kim, Taejong Paik, Lingyao Meng, Pil Sung Jo, James M. Kikkawa, Cherie R. Kagan, Mark G. Allen, Christopher B. Murray, Alternate current magnetic property characterization of nonstoichiometric zinc ferrite nanocrystals for inductor fabrication via a solution based process, J. Appl. Phys. 119 (2016) 113901(1-10). https://doi.org/10.1063/1.4942865

[22] A. Sutka, G. Mezinskis, A. Lusis, D. Jakovlevs, Chemical Influence of iron non-stoichiometry on spinel zinc ferrite gas sensing properties, Sensors Actuators B. Chem. 171 (2012) 204-209. https://doi.org/10.1016/j.snb.2012.03.012

[23] E. E. Ateia , A. T. Mohamed, Nonstoichiometry and phase stability of Al and Cr substituted $\mathrm{Mg}$ ferrite nanoparticles synthesized by citrate method, J. Magn. Magn. Mater. 426 (2017) 217-224. https://doi.org/10.1016/j.jmmm.2016.11.053

[24] B. Nandan, M. C. Bhatnagar, S. C. Kashyap, Cation distribution in nanocrystalline cobalt substituted nickel ferrites: X-ray diffraction and Raman spectroscopic investigations, J. Phys. Chem. Solids 129 (2019) 298-306. https://doi.org/10.1016/j.jpcs.2019.01.017

[25] R. C. Kambale, P. A. Shaikh, S. S. Kamble, Y. D. Kolekar, Effect of cobalt substitution on structural, magnetic and electric properties of nickel ferrite, J. Alloys Compd. 478 (2009) 599603. https://doi.org/10.1016/j.jallcom.2008.11.101

[26] Sagar E. Shirsath, Xiaoxi Liu, M. H. N. Assadi, Adnan Younis, Yukiko Yasukawa, Sumanta Kumar Karan, Ji Zhang, Jeonghun Kim, Danyang Wang, Akimitsu Morisako, Yusuke Yamauchi, $\mathrm{Sean} \mathrm{Li}, \mathrm{Au}$ quantum dots engineered room temperature crystallization and magnetic anisotropy in $\mathrm{CoFe}_{2} \mathrm{O}_{4}$ thin films, Nanoscale Horizons 4 (2019) 434-444. https://doi.org/10.1039/c8nh00278a

[27] G. P. D. Peddis, N Yaacoub, M. Ferretti, A. Martinelli, D. F. A. Musinu, C. Cannas, G. Navarra, J. M. Greneche, Cationic distribution and spin canting in $\mathrm{CoFe}_{2} \mathrm{O}_{4}$ nanoparticles, J. Phys. Condens. Matter 23 (2011) 1-8. https://doi.org/10.1088/0953-8984/23/42/426004

[28] A. M. Wahba, M. Bakr Mohamed, Structural and magnetic characterization and cation distribution of nanocrystalline $\mathrm{Co}_{x} \mathrm{Fe}_{3-x} \mathrm{O}_{4}$ ferrites, J. Magn. Magn. Mater. 378 (2015) 246-252. https://doi.org/10.1016/j.jmmm.2014.10.164

[29] V. Nica, G. Daniel, C. Ursu, F. Tudorache, F. Brinza, A. Pui, Synthesis and characterization of co-substituted ferrite nanocomposites, IEEE Trans. Magn. 49 (2013) 26-29.

https://doi.org/10.1109/TMAG.2012.2217116 
[30] A. Lassoued, J. F. Li, Magnetic and photocatalytic properties of Ni-Co ferrites, Solid State Sci. 104 (2020) 106199(1-13). https://doi.org/10.1016/j.solidstatesciences.2020.106199

[31] Mohd. Hashim, Alimuddin, Shalendra Kumar, Sagar E. Shirsath, R.K. Kotnala, Jyoti Shah, Ravi Kumar, Synthesis and characterizations of $\mathrm{Ni}^{2+}$ substituted cobalt ferrite nanoparticles, Mater. Chem. Phys. 139 (2013) 364-374. https://doi.org/10.1016/j.matchemphys.2012.09.019

[32] R. S. Melo, P. Banerjee, A. Franco, Hydrothermal synthesis of nickel doped cobalt ferrite nanoparticles: optical and magnetic properties, J. Mater. Sci. Mater. Electron. 29 (2018) 1465714667. https://doi.org/10.1007/s10854-018-9602-2

[33] P. A. Shaikh, R. C. Kambale, A. V. Rao, Y. D. Kolekar, Structural, magnetic and electrical properties of Co-Ni-Mn ferrites synthesized by co-precipitation method, J. Alloys Compd. 492 (2010) 590-596. https://doi.org/10.1016/j.jallcom.2009.11.189

[34] A. K. Zak, W. H. A. Majid, M. E. Abrishami, R. Youse, X-ray analysis of ZnO nanoparticles by Williamson e Hall and size e strain plot methods, Solid State Sci. 13 (2011) 251-256. https://doi.org/10.1016/j.solidstatesciences.2010.11.024

[35] M. George, A. Mary John, S. S. Nair, P. A. Joy, M. R. Anantharaman, Finite size effects on the structural and magnetic properties of sol-gel synthesized $\mathrm{NiFe}_{2} \mathrm{O}_{4}$ powders, J. Magn. Magn. Mater. 302 (2006) 190-195. https://doi.org/10.1016/j.jmmm.2005.08.029

[36] V. K. Chakradhary, A. Ansari, M. J. Akhtar, Design, synthesis, and testing of high coercivity cobalt doped nickel ferrite nanoparticles for magnetic applications, J. Magn. Magn. Mater. 469 (2019) 674-680. https://doi.org/10.1016/j.jmmm.2018.09.021

[37] B. Ali, S. M. Tasirin, P. Aminayi, Z. Yaakob, N. T. Ali, W. Noori, Non-supported nickel-based coral sponge-like porous magnetic alloys for catalytic production of syngas and carbon bionanofilaments via a biogas decomposition approach, Nanomaterials 8 (2018) 1-28. https://doi.org/10.3390/NANO8121053

[38] J. M. Yang, W. J. Tsuo, F. S. Yen, Preparation of Ultrafine Nickel Ferrite Powders Using Mixed Ni and Fe Tartrates, J. Solid State Chem. 145 (1999) 50-57. https://doi.org/10.1006/jssc.1999.8215

[39] X. Wu, W. Chen, W. Wu, J. Wu, Q. Wang, Improvement of the magnetic moment of NiZn ferrites induced by substitution of $\mathrm{Nd}^{3+}$ ions for $\mathrm{Fe}^{3+}$ ions, J. Magn. Magn. Mater. 453 (2018) 246-253. https://doi.org/10.1016/j.jmmm.2018.01.057

[40] M. Mozaffari, J. Amighian, E. Darsheshdar, Magnetic and structural studies of nickel-substituted cobalt ferrite nanoparticles, synthesized by the sol-gel method, J. Magn. Magn. Mater. 350 (2014) 19-22. https://doi.org/10.1016/j.jmmm.2013.08.008

[41] A. Kuwabara, C. A. J. Fisher, Y. H. Ikuhara, H. Moriwake, H. Oki, Y. Ikuhara, The influence of charge ordering on the phase stability of spinel $\mathrm{LiNi}_{2} \mathrm{O}_{4}, \mathrm{RSC}$ Adv. 2 (2012) 12940-12948. https://doi.org/10.1039/c2ra21043f

[42] C. Sujatha, K. Venugopal Reddy, K. Sowri Babu, A. Ramachandra Reddy, and K. H. Rao, Effect 
of sintering temperature on electromagnetic properties of NiCuZn ferrite, Ceram. Int. 39 (2013) 3077-3086. http://doi.org/10.1016/j.ceramint.2012.09.087

[43] B. Gillot, P. Tailhades, Temperature dependence of oxidation behavior and coercivity evolution in fine-grained spinel ferrites, J. Magn. Magn. Mater. 208 (2000) 181-187. https://doi.org/10.1016/S0304-8853(99)00591-0

[44] J. S. Ghodake, R. C. Kambale, S. V. Salvi, S. R. Sawant, S. S. Suryavanshi, Electric properties of Co substituted Ni-Zn ferrites, J. Alloys Compd. 486 (2009) 830-834. https://doi.org/10.1016/j.jallcom.2009.07.075

[45] I. H. Gul, E. Pervaiz, Comparative study of $\mathrm{NiFe}_{2-x} \mathrm{Al}_{x} \mathrm{O}_{4}$ ferrite nanoparticles synthesized by chemical co-precipitation and sol-gel combustion techniques, Mater. Res. Bull. 47 (2012) 13531361. https://doi.org/10.1016/j.materresbull.2012.03.005

[46] H. Parmar, R. V. Upadhyay, S. Rayaprol, V. Siruguri, Structural and magnetic properties of nickel-zinc ferrite nanocrystalline magnetic particles prepared by microwave combustion method, Indian J. Phys. 88 (2014) 1257-1264. https://doi.org/10.1007/s12648-014-0576-5

[47] H. Zhang, A. Chang, C. Peng, Preparation and characterization of $\mathrm{Fe}^{3+}$-doped Ni ${ }_{0.9} \mathrm{Co}_{0.8} \mathrm{Mn}_{1.3-x} \mathrm{Fe}_{x} \mathrm{O}_{4}(0 \leq x \leq 0.7)$ negative temperature coefficient ceramic materials. Microelectron, Eng. 88 (2011) 2934-2940. https://doi.org/10.1016/j.mee.2011.04.023

[48] K. S. Rao, G. S. V. R. K. Choudary, K. H. Rao, C. Sujatha, Structural and Magnetic Properties of Ultrafine $\mathrm{CoFe}_{2} \mathrm{O}_{4}$ Nanoparticles, Procedia Mater. Sci. 10 (2015) 19-27. https://doi.org/10.1016/j.mspro.2015.06.019

[49] H. Du, X. Yao, L. Zhang, Structure, IR spectra and dielectric properties of $\mathrm{Bi}_{2} \mathrm{O}_{3}-\mathrm{ZnO}-\mathrm{SnO}_{2}-$ $\mathrm{Nb}_{2} \mathrm{O}_{5}$ quarternary pyrochlore, Ceram. Int. 28 (2002) 231-234. https://doi.org/10.1016/S02728842(01)00084-0

[50] R. Tiwari, M. De, H. S. Tewari, S. K. Ghoshal, Structural and magnetic properties of tailored $\mathrm{NiFe}_{2} \mathrm{O}_{4}$ nanostructures synthesized using auto-combustion method, Results Phys. 16 (2020) 1-8. https://doi.org/10.1016/j.rinp.2019.102916

[51] B. P. Barbero, J. A. Gamboa, L. E. Cadús, Synthesis and characterisation of $\mathrm{La}_{1-x} \mathrm{Ca}_{x} \mathrm{FeO}_{3}$ perovskite-type oxide catalysts for total oxidation of volatile organic compounds, Appl. Catal. B Environ. 65 (2006) 21-30. https://doi.org/10.1016/j.apcatb.2005.11.018

[52] A. Gholizadeh, The effects of A/B-site substitution on structural, redox and catalytic properties of lanthanum ferrite nanoparticles, J. Mater. Res. Technol. 8 (2019) 457-466. https://doi.org/10.1016/j.jmrt.2017.12.006

[53] Z. K. Heiba, M. B. Mohamed, A. M. Wahba, M. I. Almalowi, Effect of vanadium doping on structural and magnetic properties of defective nano-nickel ferrite, Appl. Phys. A Mater. Sci. Process. 124 (2018) 1-9. https://doi.org/10.1007/s00339-018-1721-3

[54] Zhenhong Tan, Takashi Saito, Fabio Denis Romero, Midori Amano Patino, Masato Goto, Wei- 
Tin Chen, Yu-Chun Chuang, Hwo-Shuenn Sheu, Yuichi Shimakawa, Hexagonal Perovskite $\mathrm{Ba}_{4} \mathrm{Fe}_{3} \mathrm{NiO}_{12}$ Containing Tetravalent Fe and Ni Ions, Inorg. Chem. 57 (2018) 10410-10415. https://doi.org/10.1021/acs.inorgchem.8b01618

[55] Charmi D. Patel, Preksha N. Dhruv, Sher Singh Meena, Charanjeet Singh, Srikanti Kavita, Mohamed Ellouze, Rajshree B. Jotania, Influence of $\mathrm{Co}^{4+}-\mathrm{Ca}^{2+}$ substitution on structural, microstructure, magnetic, electrical and impedance characteristics of M-type barium-strontium hexagonal ferrites, Ceram. Int. 46 (2020) 24816-24830.

https://doi.org/10.1016/j.ceramint.2020.05.326

[56] K. M. Batoo, F. A. Mir, M.-S. Abd El-sadek, M. Shahabuddin, N. Ahmed, Extraordinary high dielectric constant, electrical and magnetic properties of ferrite nanoparticles at room temperature, J. nanoparticle Res. 15 (2013) 2067(1-9). https://doi.org/10.1007/s11051-013-2067-6

[57] L. Kumar, M. Kar, Influence of $\mathrm{Al}^{3+}$ ion concentration on the crystal structure and magnetic anisotropy of nanocrystalline spinel cobalt ferrite, J. Magn. Magn. Mater. 323 (2011) 2042-2048. https://doi.org/10.1016/j.jmmm.2011.03.010

[58] C. N. Chinnasamy, M. Senoue, B. Jeyadevan, O. Perales-Perez, K. Shinoda, K. Tohji, Synthesis of size-controlled cobalt ferrite particles with high coercivity and squareness ratio, J. Colloid Interface Sci. 263 (2003) 80-83. https://doi.org/10.1016/S0021-9797(03)00258-3

[59] G. F. Dionne, Electron Spins in Ionic Molecular Structures. In Magnetic Interactions and Spin Transport, Springer (2003) 1-130.

[60] Simi Debnath, Ratan Das, Cobalt doping on nickel ferrite nanocrystals enhances the microstructural and magnetic properties: Shows a correlation between them, J. Alloys Compd. 852 (2021) 156884(1-14). https://doi.org/10.1016/j.jallcom.2020.156884 
Figures

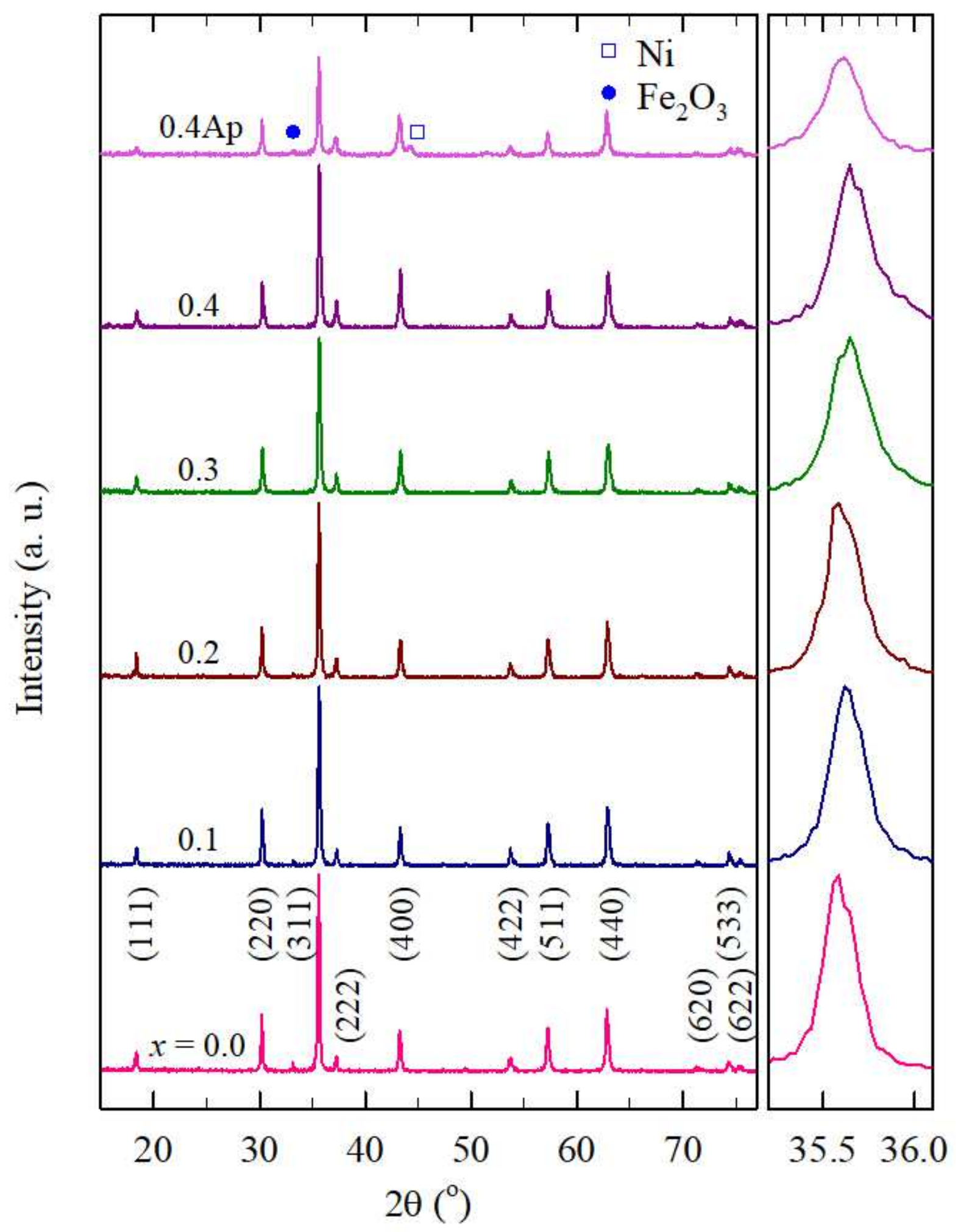

Figure 1

XRD Pattern for Co0.5Ni0.5+xFe2-xO4 $(0 \leq \mathrm{x} \leq 0.4)$ samples sintered at $600^{\circ} \mathrm{C}$ and for as-prepared Co0.5Ni0.9Fe1.604 one (0.4Ap). 


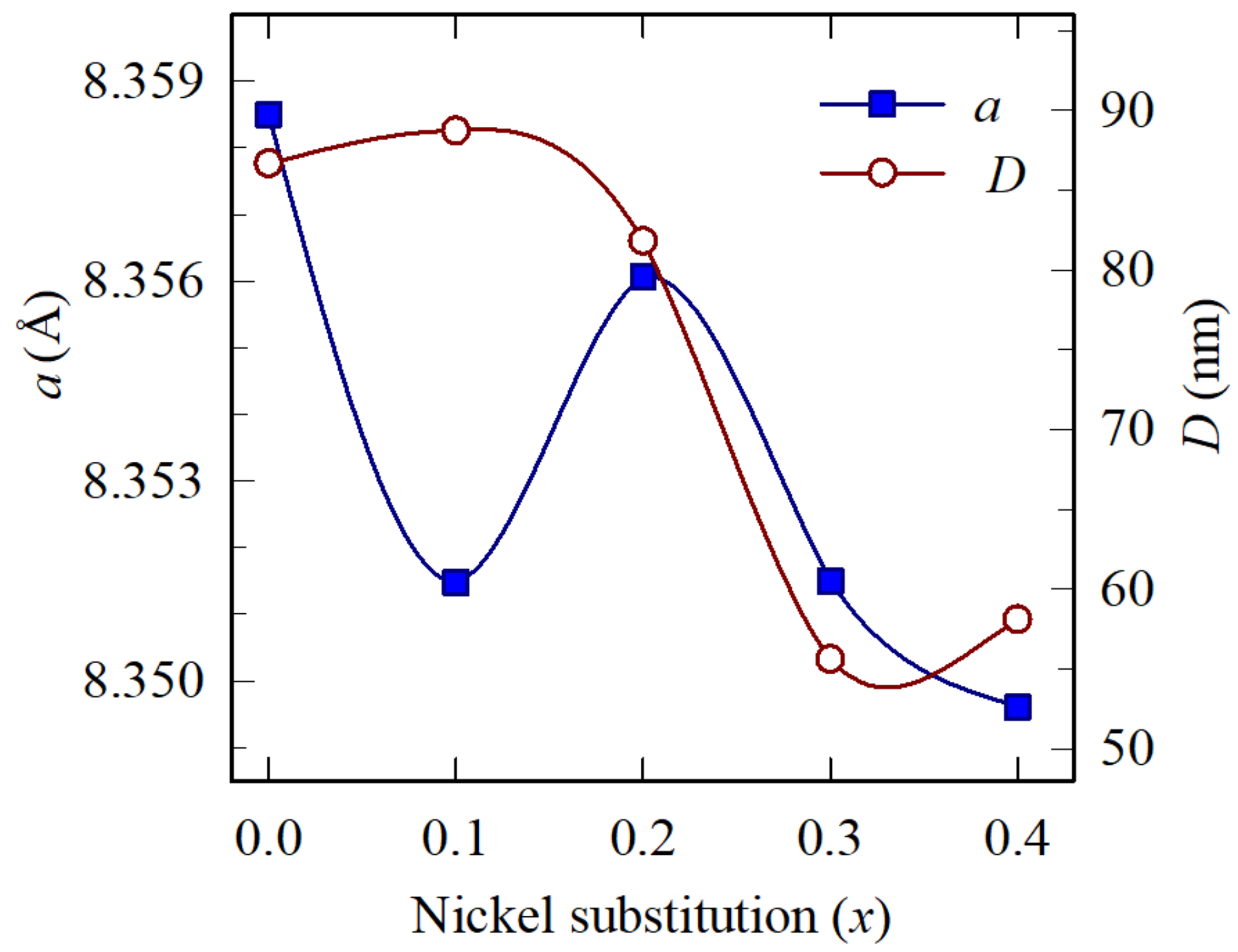

Figure 2

The variation of the lattice parameter (a) and the crystallite size (D) with nickel substitution for Co0.5Ni0.5+xFe2-xO4 samples sintered at $600^{\circ} \mathrm{C}$. 

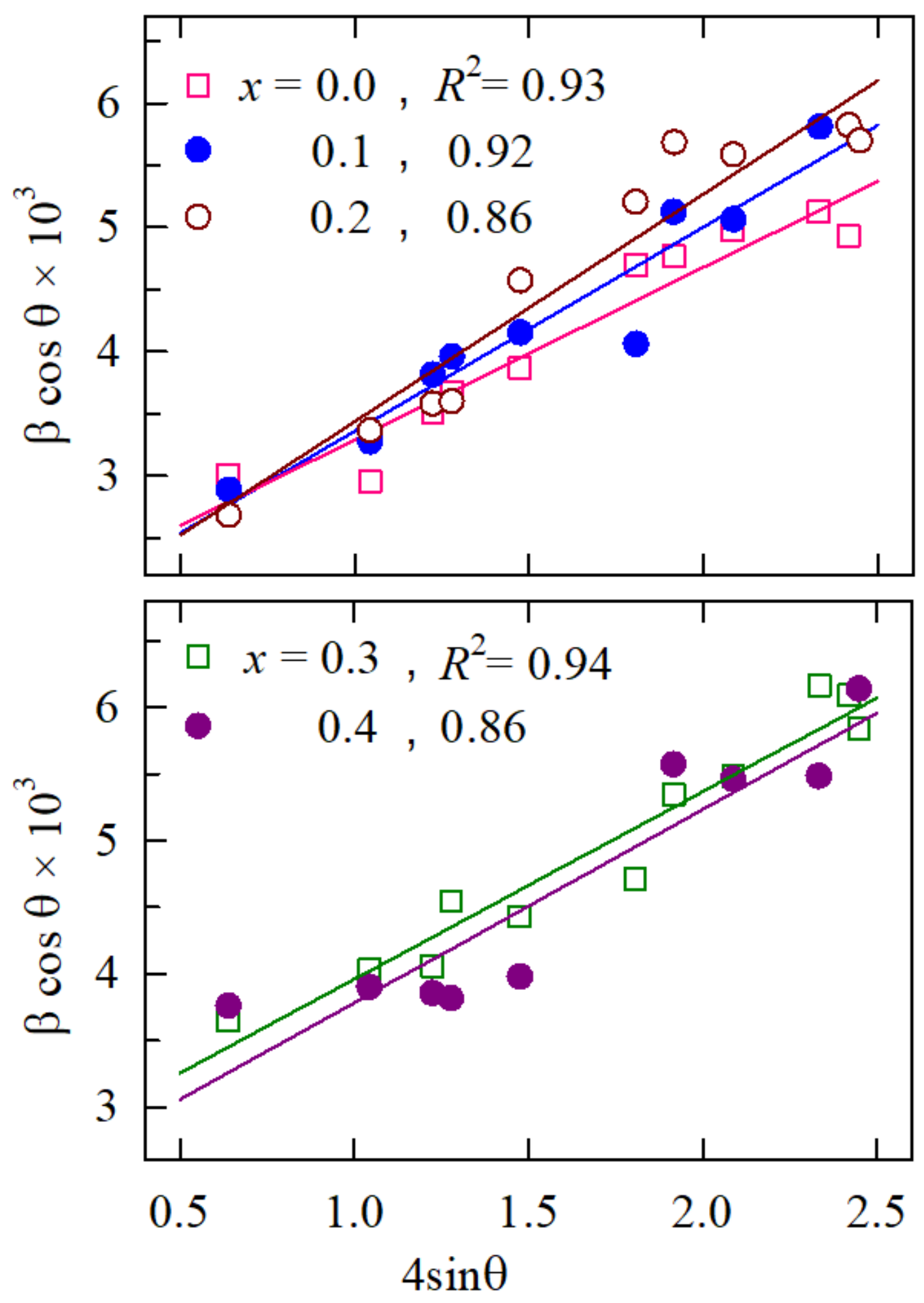

Figure 3

Williamson- Hall plots for Co0.5Ni0.5+xFe2-xO4 sintered samples $(0.0 \leq x \leq 0.4)$ 


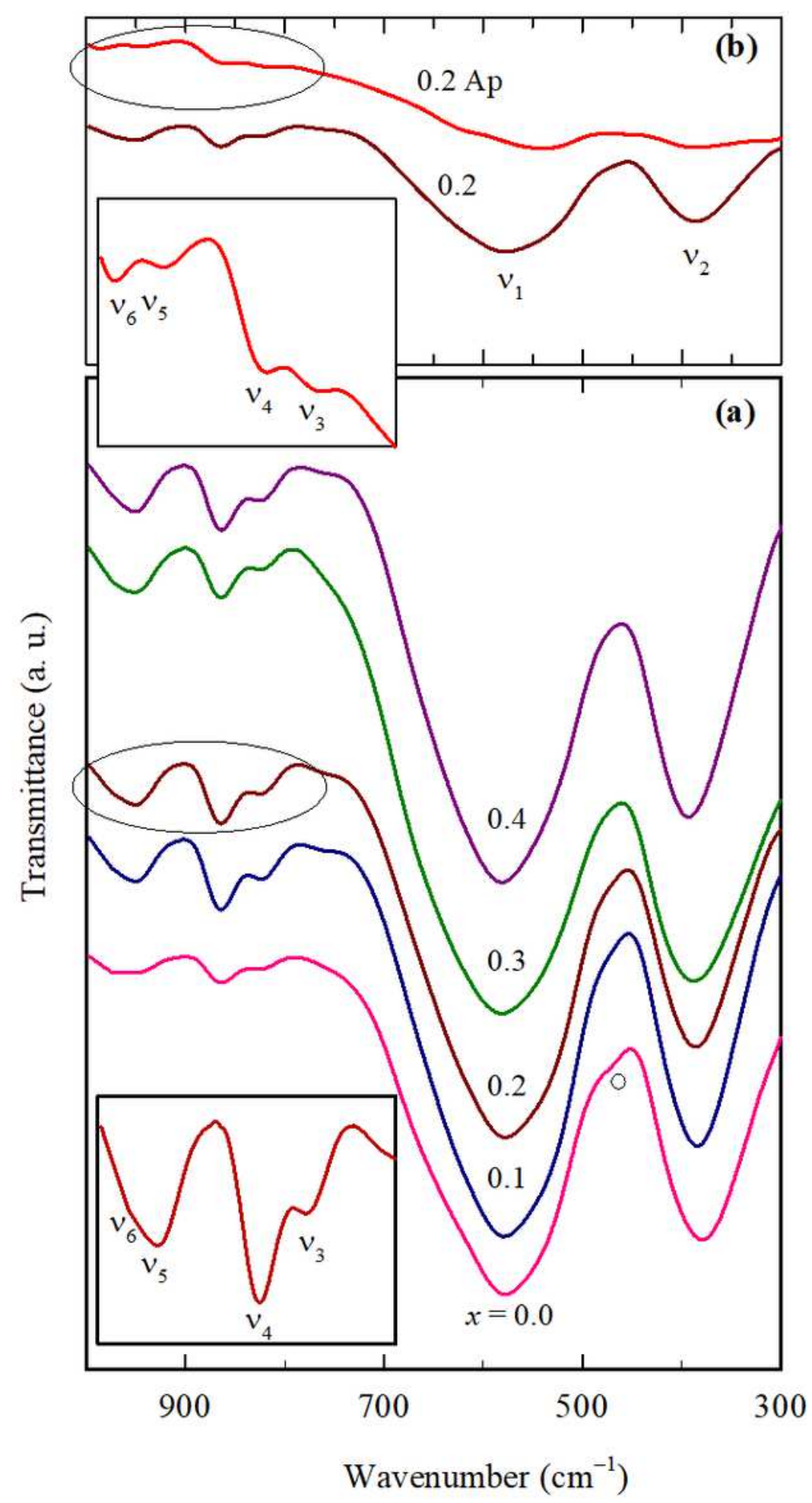

Figure 4

(a) FTIR spectra for sintered samples of Co0.5Ni0.5+xFe2-xO4 (0.0 $\leq x \leq 0.4)$ and (b) for Ap and sintered samples with $x=0.2$. Insets clarify the faint high-frequency absorption bands. 


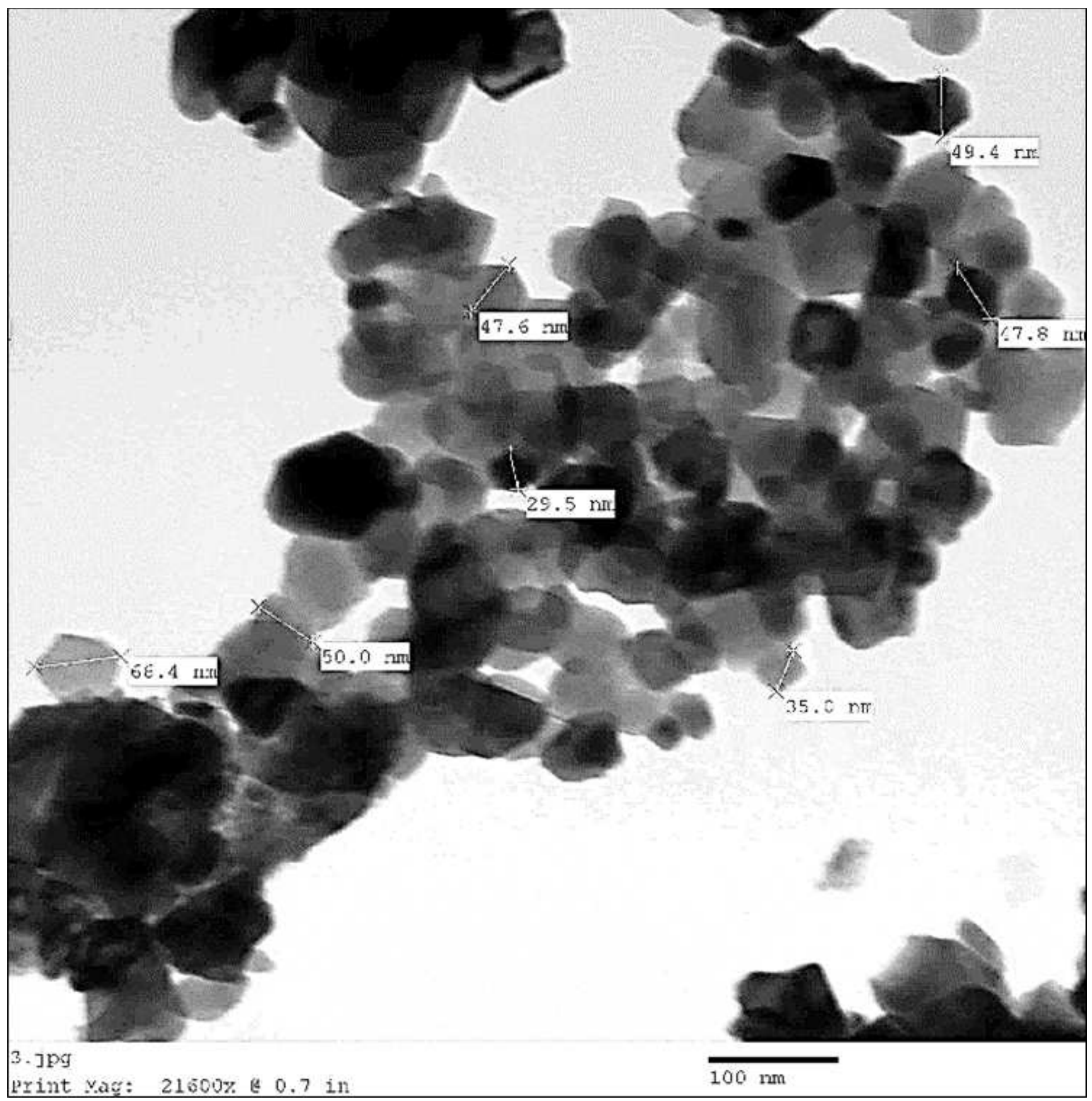

Figure 5

TEM image for Co0.5Ni0.9Fe1.604 sample sintered at $600^{\circ} \mathrm{C}$. 


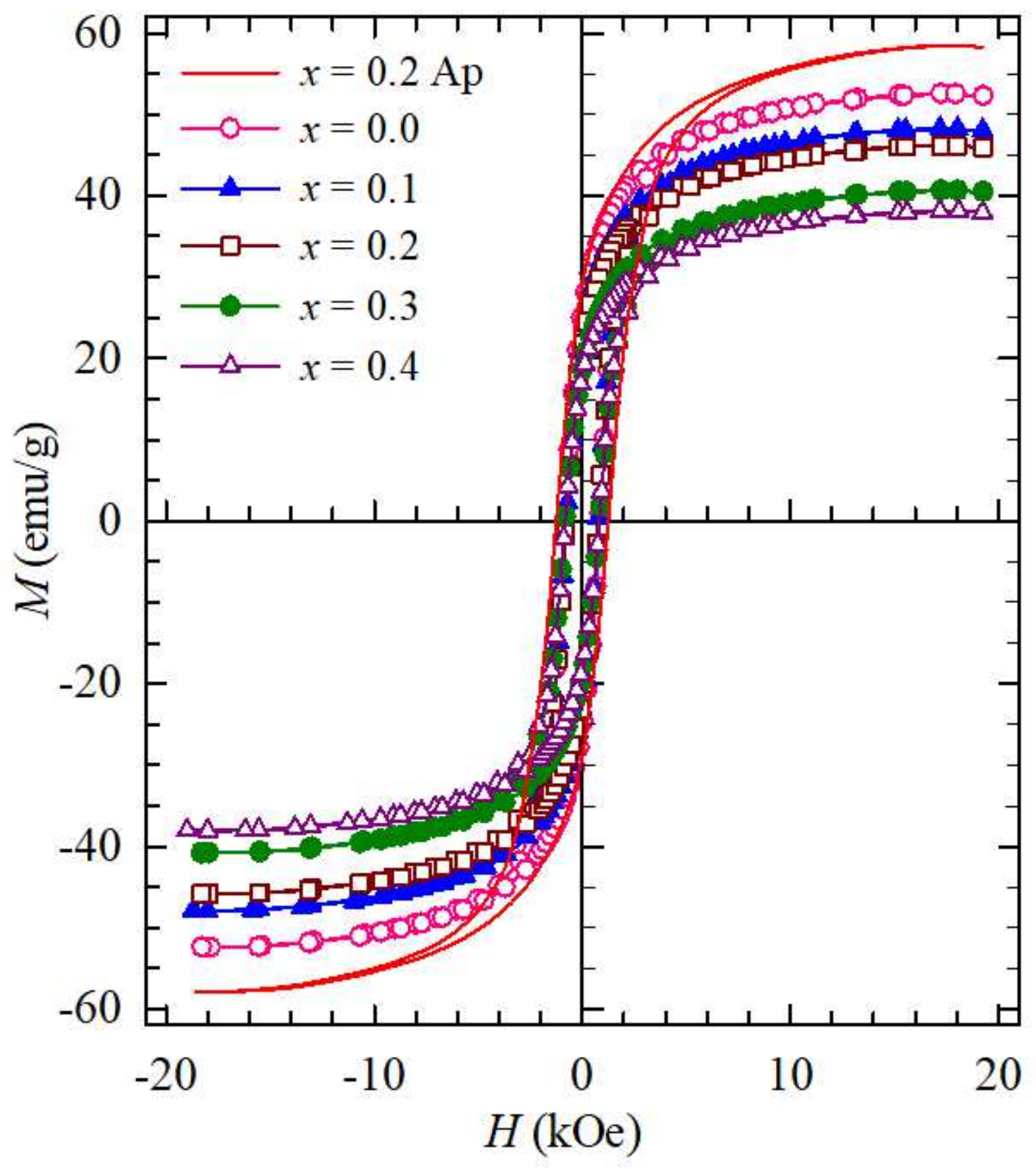

Figure 6

$\mathrm{M}-\mathrm{H}$ hysteresis loops for $\mathrm{Co} 0.5 \mathrm{Ni0} .5+\mathrm{xFe} 2-\mathrm{xO} 4(0.0 \leq \mathrm{x} \leq 0.4)$ samples sintered at $600{ }^{\circ} \mathrm{C}$ for $2 \mathrm{~h}$. 


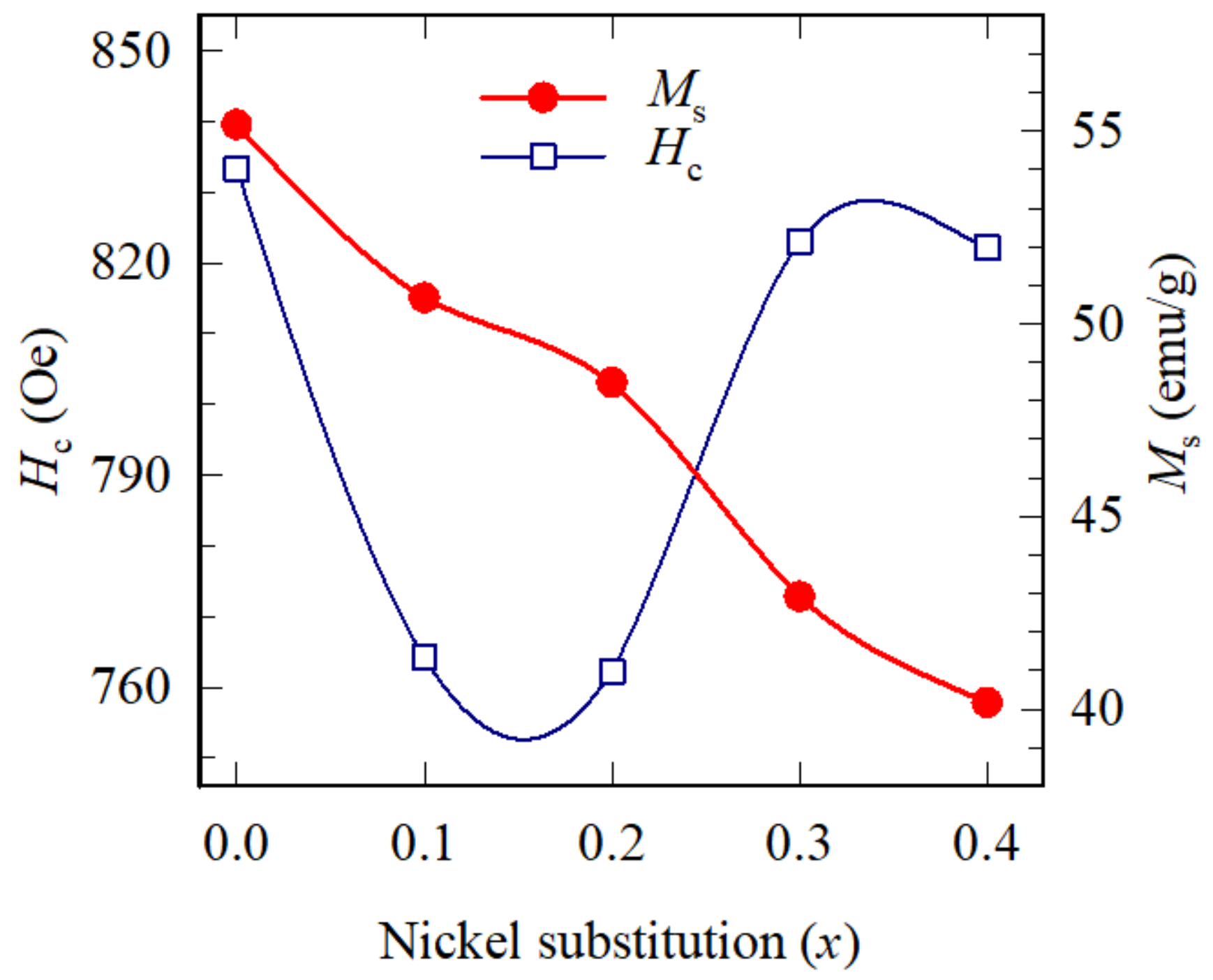

Figure 7

Dependence of saturation magnetization (Ms) and coercivity $(\mathrm{Hc})$ on the nickel substitution for Co0.5Ni0.5+xFe2-xO4 sintered samples. 


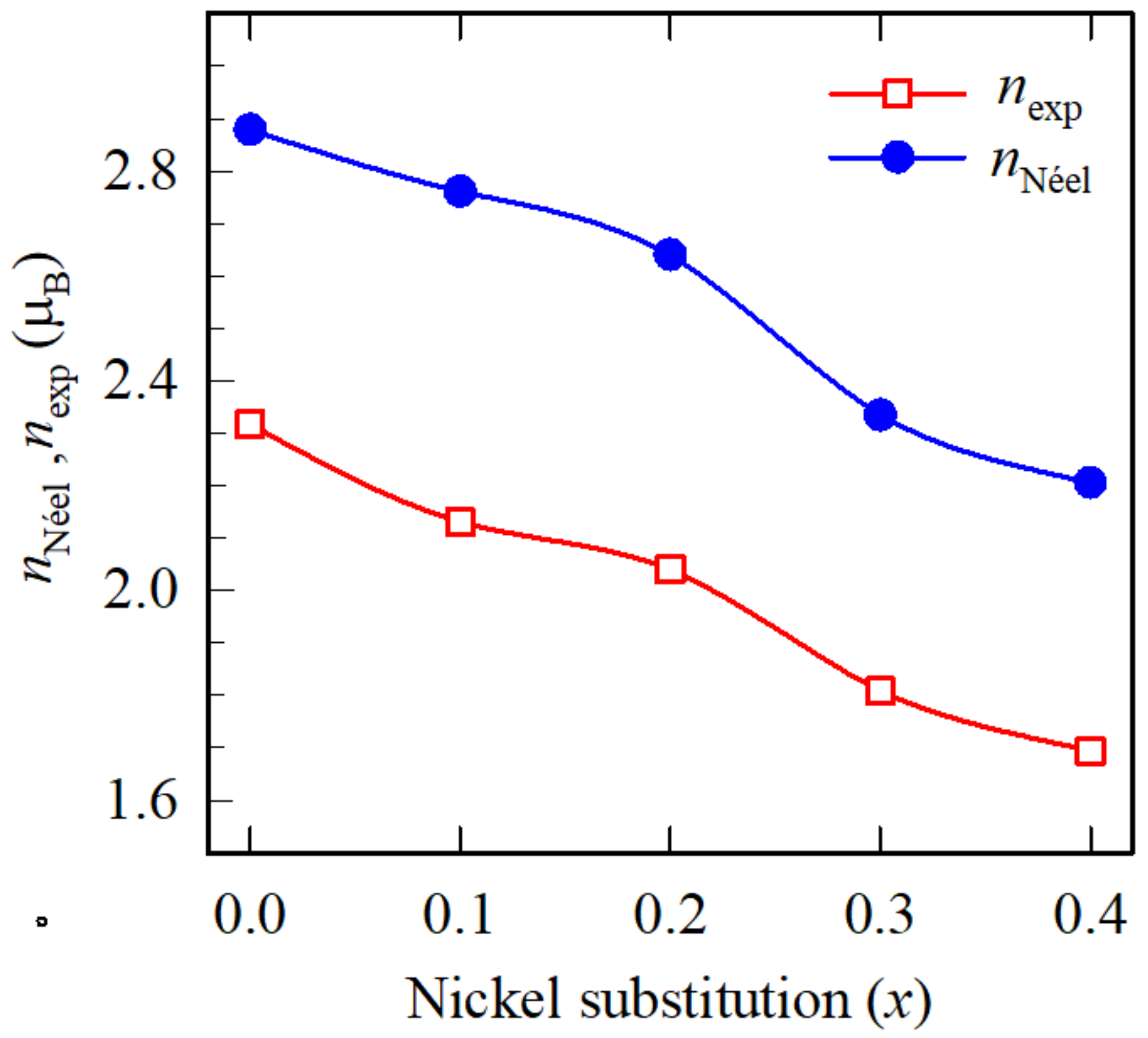

Figure 8

The variation of the experimental magnetic moment (nexp) and that estimated from the proposed cation distribution (nNéel) with $\mathrm{Ni}$ substitution for $\mathrm{Co} 0.5 \mathrm{Ni0} .5+\mathrm{xFe} 2-\mathrm{xO} 4$ sintered samples. 

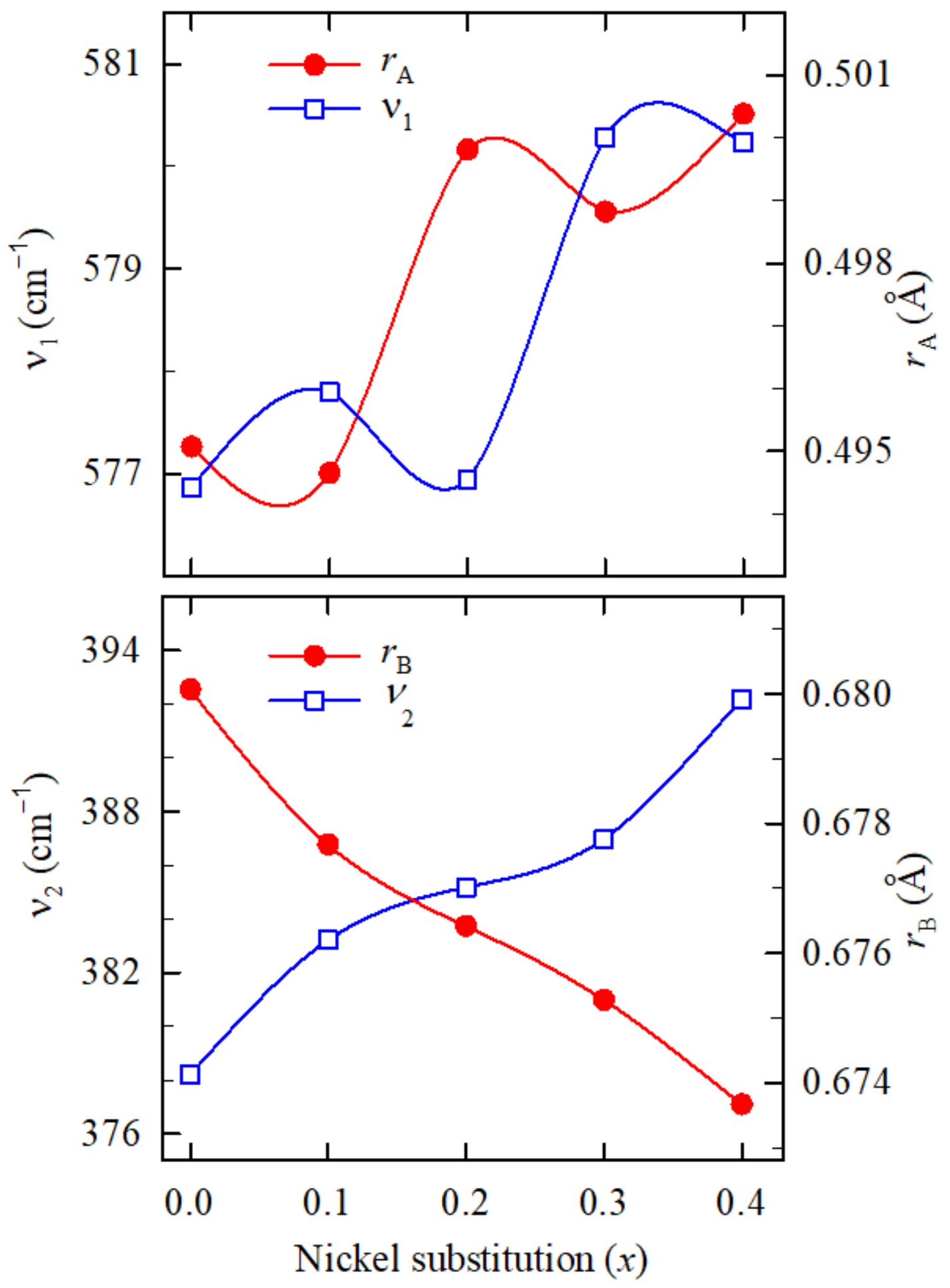

Figure 9

The variation of sublattice radii ( $\mathrm{rA}$ and $\mathrm{rB})$, estimated from the cation distribution, and IR vibrational frequencies ( $\mathrm{v} 1$ and v2), from IR spectra, with Ni substitution for sintered Co0.5Ni0.5+xFe2-xO4 samples. 


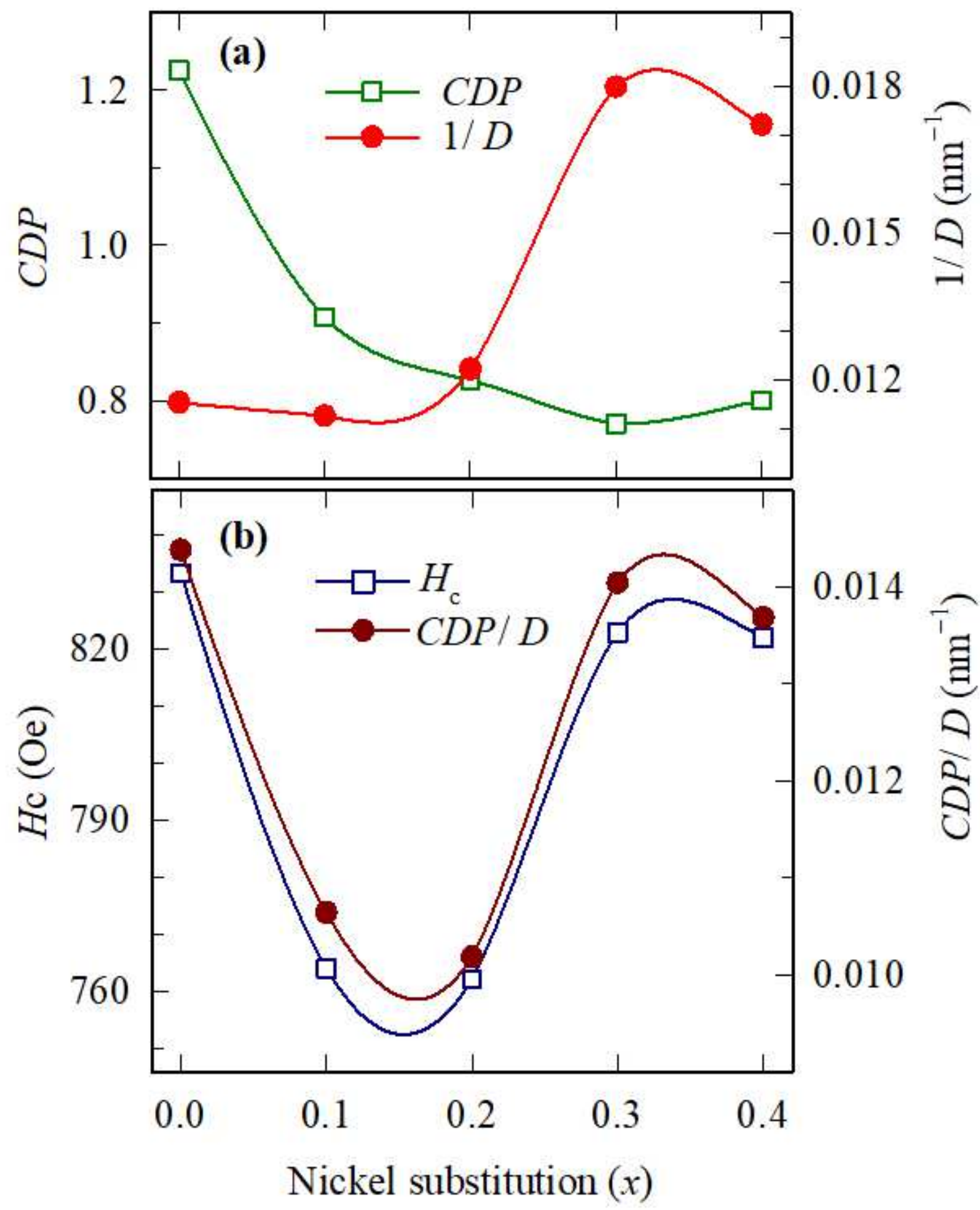

Figure 10

(a) Variation of CDP and 1/D with nickel substitution ( $\mathrm{x}$ ) for Co0.5Ni0.5+xFe2-xO4 sintered samples, and (b) the corresponding variation of coercivity $(\mathrm{Hc})$ and the quotient CDP/D. 


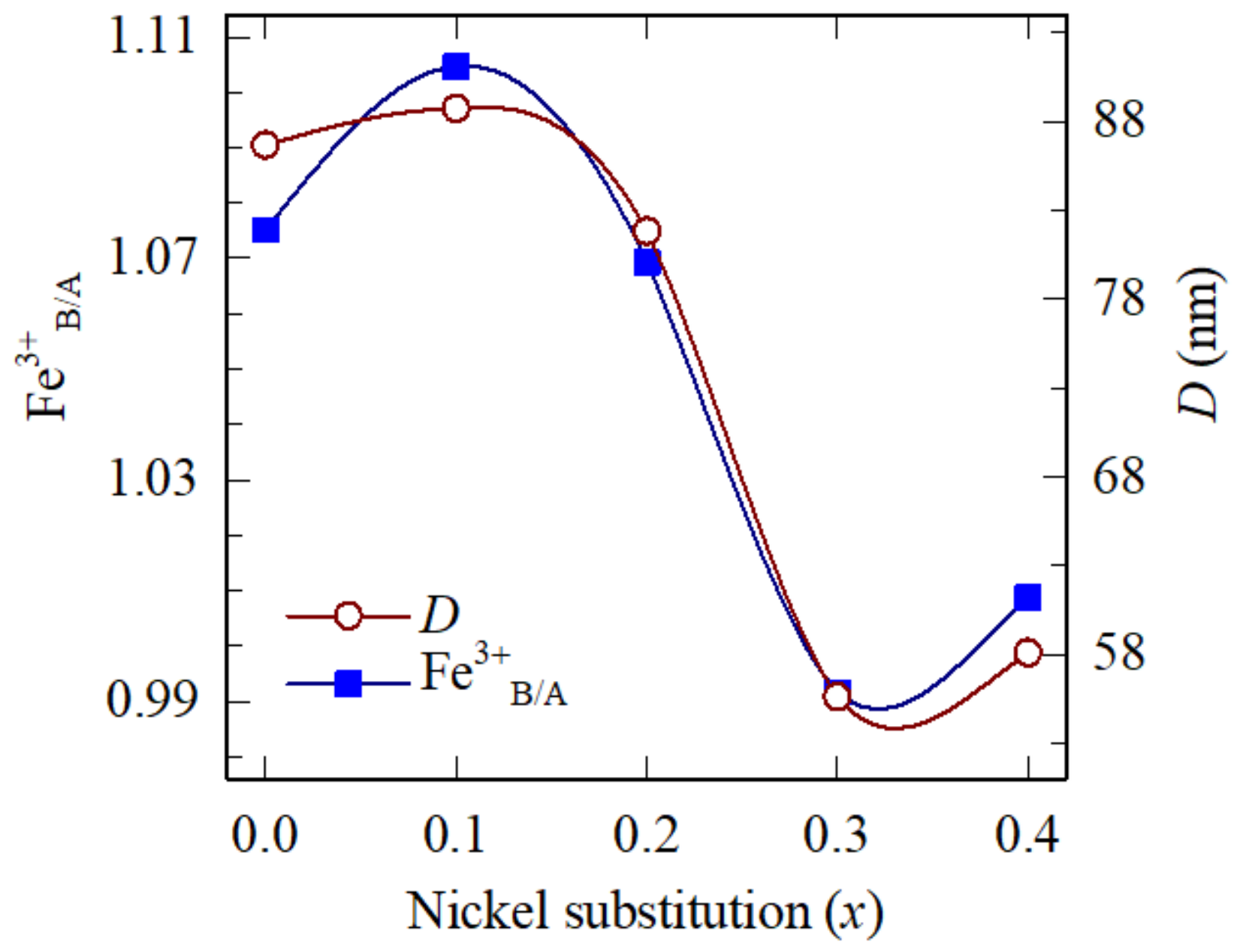

Figure 11

The variation of the estimated $\mathrm{Fe} 3+\mathrm{B} / \mathrm{A}$ and the crystallite size $\mathrm{D}$ with Ni substitution for sintered Co0.5Ni0.5+xFe2-xO4 samples.

\section{Supplementary Files}

This is a list of supplementary files associated with this preprint. Click to download.

- CoNixFexTables210114.docx 